\title{
Capítulo 1 - 0 enigma do pulgão
}

\author{
Filipe Faria Berçot \\ Maria Elice de Brzezinski Prestes
}

\section{SciELO Books / SciELO Livros / SciELO Libros}

BERÇOT, F.F., and PRESTES, M.E.B. O enigma do pulgão. In: MOURA, B. A., and FORATO, T. C. M., comps. Histórias das ciências, epistemologia, gênero e arte: ensaios para a formação de professores [online]. São Bernardo do Campo, SP: Editora UFABC, 2017, pp. 11-35. ISBN 978-85-68576-84-7. https://doi.org/10.7476/9788568576847.0002.

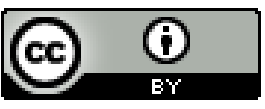

All the contents of this work, except where otherwise noted, is licensed under a Creative Commons Attribution 4.0 International license.

Todo o conteúdo deste trabalho, exceto quando houver ressalva, é publicado sob a licença Creative Commons Atribição $\underline{4.0}$.

Todo el contenido de esta obra, excepto donde se indique lo contrario, está bajo licencia de la licencia $\underline{\text { Creative }}$ Commons Reconocimento 4.0. 


\section{O ENIGMA DO PULGÃO}

Filipe Faria Berçot Maria Elice de Brzezinski Prestes

\section{Introdução}

Este capítulo apresenta o episódio histórico da "descoberta" da multiplicação sem acasalamento (partenogênese) em pulgões, realizada pelo naturalista genebrês Charles Bonnet (1720-1793) na primeira metade do século XVIII. O fenômeno da geração dos seres vivos ocupou o centro das atenções dos estudos de história natural naquele século. O impacto dessa descoberta, de uma forma de reprodução animal antes impensável, causou rearranjo conceitual do tema e consolidação de novos modelos metodológicos de investigação. Assim, além da descoberta mencionada, o capítulo salienta regras, procedimentos e técnicas de observação e experimentos que se caracterizaram como elementos de inovação metodológica no campo de estudo do funcionamento dos organismos vivos na época.

O capítulo realça, ainda, as relações de Bonnet com um naturalista já afamado do período, o francês René Antoine Ferchault de Réaumur (1683-1757). Dentre os diversos estudos realizados por Réaumur, foi expressiva a sua contribuição para o 
conhecimento dos "insetos", termo empregado na época para referir a toda sorte de organismos pequenos (PRESTES, 2008, p. 270). Além de difundir conhecimentos sobre a "insectologia", as publicações de Réaumur aspiravam também impelir a curiosidade e estimular novas investigações no âmbito da história natural voltada aos organismos inferiores. Será mostrado, então, de que modo o apelo de Réaumur atraiu as atenções do jovem Bonnet, ilustrando as redes de relações acadêmicas no século XVIII.

A abordagem histórica é acompanhada de discussões que subsidiam a sua incorporação em práticas de ensino de biologia, da escola básica e/ou ensino superior. Dentre os vários benefícios que a literatura da área (MATTHEWS, 1994; MARTINS, 1998; MARTINS, 2006) indica sobre a utilização da história da ciência no ensino estão a facilitação para a aprendizagem significativa de conhecimento científico atual e o desenvolvimento, por meio de abordagem explícita e reflexiva, de visão informada e fundamentada sobre o modo como a ciência funciona (METZ, 2007; ALLCHIN, 2012, 2013).

Assim, o episódio histórico é aqui discutido com o objetivo de constituir material instrucional alternativo segundo dois objetivos principais: facilitar a aprendizagem de conceitos biológicos importantes, no caso, a partenogênese, relacionada ao tema da reprodução assexuada de animais; e promover discussão explícita e reflexiva de aspectos metacientíficos, no caso, questões relacionadas à dimensão "sociocultural" da ciência, que, juntamente às dimensões "observacional" e "conceitual", constitui o que Allchin (2013) chamou de "Ciência Integral" (Whole Science). A abordagem de Allchin foi adotada neste trabalho como uma proposta de superação do enfoque sobre listas "consensuais" de aspectos de Natureza da Ciência (ERDURAN; DAGHER, 2016, p. 1). 
O estudo histórico seguiu a metodologia de pesquisa em história da ciência, com base na análise de fontes primárias dos autores já mencionados. De Bonnet, foi analisado, especialmente, o Traité d'Insectologie ou Observation sur lês Pucerons (Tratado de insetologia ou observações sobre pulgões), publicado em 1745. De Réaumur, foi realizada análise dos textos sobre as lagartas processionárias e pulgões contidos nos volumes 1 e 3 de suas Memóires pour servir a l'histoire des insectes (Memórias para servir à história dos insetos), obra com seis volumes publicados entre 1734 e 1742. Paralelamente, foi realizada a análise das fontes secundárias pertinentes, isto é, obras de historiadores da ciência que se debruçaram sobre as contribuições dos naturalistas mencionados, servindo como guias de orientação para a leitura, auxiliando na contextualização epistêmica e social de suas obras. Os percursos particulares da formação, carreira e produção acadêmica dos autores foram levantados junto a obras biográficas e enciclopédicas.

Além disso, foram consultados trabalhos recentes de pesquisadores ocupados com a inserção da história da ciência no ensino, além de publicações de especialistas das ciências biológicas para comparação com o conhecimento atual sobre os fenômenos descritos.

\section{Bonnet, Réaumur e a insetologia}

Charles Bonnet era membro de uma família de magistrados aristocratas de Genebra. Seguindo a orientação de seu pai, obteve o título de Doutor em Lei aos 23 anos, mas nunca desempenhou a profissão de advogado. Desde a adolescência, o seu grande fascínio e vocação foi pela história natural, sobretudo a história natural dos insetos. 
A história a seguir narra alguns dos acontecimentos que levaram Bonnet a se tornar o correspondente mais jovem da Academia de Ciências de Paris, um conceituado centro de estudos e disseminação do conhecimento em história natural da época.

Aos 17 anos, Bonnet não apenas realizava leituras, mas repetia e conduzia novas observações com insetos sugeridas nas obras de Réaumur: "Observei pela primeira vez em maio de 1737 e vi tudo aquilo que o Sr. Réaumur contou em detalhes [...]" (BONNET, 1779, p. 13). Um estudo em particular, sobre os hábitos da "lagarta processionária"1 (RÉAUMUR, 1736, p. 161) levou Bonnet a desenvolver uma forma sistemática de observação. A Figura 1 ilustra as lagartas processionárias observadas por Réaumur.

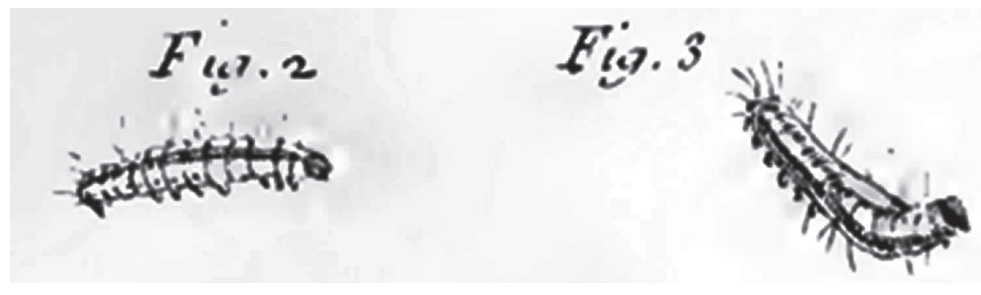

Figura 1 - llustrações das lagartas processionárias

Fonte: Réaumur (1736, prancha 10, p. 211).

No ano seguinte, Bonnet encontrou um galho contendo um ninho dessas lagartas e decidiu levá-lo para casa, alojando-o na parte externa da janela de seu quarto. Dessa forma, ele garantia que ficasse em um ambiente semelhante àquele na natureza, "ao contrário do que faziam os naturalistas, confinando

\footnotetext{
1 Lagarta processionária (Thaumetopoea pityocampa), denominada por Réaumur de Livrée é uma espécie amplamente distribuída na França e comumente encontrada sobre pinheiros (FITZGERALD, 2003).
} 
insetos em potes de vidro" (BONNET, 1779, p. 14). No decurso de alguns meses, Bonnet observou diversos comportamentos das lagartas, por exemplo: características morfológicas, reações a estímulos externos, como calor, luz e som, trocas de pele (hoje denominadas ecdises ou mudas) e a formação de casulos e crisálidas (BONNET, 1779, p. 14-28).

Uma peculiaridade dessas lagartas, relacionada ao próprio nome pelo qual eram reconhecidas, era o fato de elas caminharem a longas distâncias de seus ninhos, sempre em fila, "em procissão", e retornarem exatamente pelo mesmo caminho. Como esses insetos se orientavam por caminhos tão longos? Bonnet se propôs a entender como isso acontecia.

Eu sabia que as lagartas não eram desprovidas de visão, pois eu já tinha observado seus olhos com uma lupa [...]; mas, apesar disso, eu não estava muito seguro sobre o papel da visão dessas lagartas; e eu não estava convencido que seus olhos seriam o suficiente para guiá-las por caminhos tão diferentes e distantes. (BONNET, 1779, p. 18-19)

Numa manhã, enquanto as lagartas saíam do ninho, Bonnet notou um brilho esbranquiçado refletido pelo sol sobre a janela. Ao olhar para a base da janela, ele percebeu um fio de seda ao longo da rota e constatou que esse fio era produzido pelas próprias lagartas. Ao longo do caminho esses fios formavam um tipo de "tapete de seda" que parecia servir como trilhos de orientação. Para ter certeza de que essa "tapeçaria" era, de fato, a responsável pela condução das lagartas, ele rompeu o trilho com seu próprio dedo. Chama a atenção, na descrição de Bonnet, o detalhamento da observação e o modo como expressa o comportamento do inseto com base nas atitudes e características humanas: 
Quando a lagarta que liderava a procissão chegou ao ponto onde o caminho foi interrompido, ela virou-se imediatamente, como se estivesse assustada: (...) à medida que as demais lagartas chegavam ao ponto rompido, paravam sua marcha e pareciam mais ou menos confusas. [...] Enfim, uma das lagartas, mais corajosa que as outras, ousou continuar e traçou um novo fio para restabelecer a rota, sendo logo acompanhada pelas outras. [...] Devo dizer, no entanto, que até que a rota fosse totalmente reparada, minhas lagartas ainda mostravam certa inquietude ao passar pelo ponto danificado. (BONNET, 1779, p. 21-22)

Bonnet repetiu outras vezes esse "experimento" simples, sempre obtendo os mesmos resultados. Aqui é importante enfatizar dois aspectos; o primeiro, de que, como seus contemporâneos, Bonnet usa o termo experimento naquele sentido baconiano de qualquer alteração do curso normal da natureza; o segundo, de que ele está adotando um procedimento, a repetição do experimento, que se constitui como regra metodológica entre os naturalistas do período. Também é digno de nota o discernimento de Bonnet sobre o fato novo agregado às observações de Réaumur:

O sr. Réaumur sabia que as processionárias cobriam seu caminho com fios [...], mas ele não havia percebido todos os usos dessa manobra. Ele acreditava que as lagartas cobriam o seu caminho porque era mais fácil marchar e agarrar em folhas e galhos cobertos de [fios] seda do que sobre folhas e galhos nus. (BONNET, 1779, p. 31)

Como leitor de Réaumur, Bonnet sabia que ele era um incentivador da disseminação da prática de estudos em história natural, reconhecendo a contribuição de colegas, colaboradores 
e auxiliares que enviavam toda sorte de organismos e relatos de observações (TERRALL, 2010, p. 573). Réaumur era bastante enfático nesse convite:

Qualquer interessado no progresso da história natural, que me julgar capaz de contribuir, pode me enviar presentes os quais receberei com apreciação; eu ficarei feliz em expressar publicamente, caso me façam a gentileza de enviar observações e insetos que lhes pareçam incomuns e que desejam que eu os estude. (RÉAUMUR, 1734, p. 51)

Bonnet animou-se a enviar uma correspondência ao naturalista francês, dando origem a 19 anos de trocas de cartas entre os dois.

Cabe assinalar que, nos séculos XVII e XVIII, as cartas eram uma forma bastante comum de comunicação entre estudiosos e constituíam modalidade padrão de disseminação do conhecimento. Devido ao caráter rápido, barato e seguro, ganharam um nicho duradouro na troca de informações (HATCH, 2000, p. 263). Mediante o uso do transporte por cavalos (em média $8 \mathrm{~km} / \mathrm{h}$ ) ou por barcos movidos a vento (15 km/h) (RODRIGUE; COMTOIS; SLACK, 2013, p. 15), dentro de poucas semanas, cartas poderiam ser enviadas e recebidas em toda a Europa, via combinação entre a remessa normal e a diplomática (HATCH, 2000, p. 263). Isso gerou a criação de redes de correspondência que, associadas às sociedades científicas emergentes da época, reforçaram os modos tradicionais de comunicação (livro impresso) e representaram uma inovação significativa (MCCLELLAN, 2008, p. 89). Além da transferência regular de informações, as remessas asseguravam também a troca de itens colecionáveis, espécimes e obras publicadas (LEONI, 2013, p. 507). 
Réaumur ilustra bem a formação dessas redes. O prestígio e sua posição acadêmica facilitaram o estabelecimento de uma grande rede internacional composta não apenas por outros naturalistas, mas também por coletores desconhecidos e estudiosos amadores. Ele recebia organismos vivos e conservados de vários lugares do mundo, escrevia instruções sobre métodos de observação, preparação e conservação dos espécimes (RATCLIFF, 2005, p. 233).

A rede de correspondências entre esses naturalistas é um exemplo que permite reflexões sobre a dimensão sociocultural da ciência como apontado por Allchin (2013). As correspondências se configuram, do ponto de vista das instituições, em torno de aspectos como "colaboração e competição entre os cientistas" e "formas de persuasão" utilizadas, enquanto, do ponto de vista da comunicação, elas indicam as "normas de manuseio de dados científicos" (ALLCHIN, 2013, p. 24).

Seguindo o espírito enciclopedista da época, Réaumur indica a percepção de que não conseguiria elucidar sozinho o estudo dos insetos. A "insectologia" dependia de recursos materiais e contribuição intelectual que teria que provir de diferentes pessoas e de lugares diversos. Ele almejava expandir os conhecimentos incomuns e singulares não apenas a respeito da morfologia e do comportamento dos insetos, mas também de seus aspectos úteis ou nocivos para a sociedade humana (TERRALL, 2010, p. 575).

$\mathrm{E}$ no que concerne à singularidade, outro pequeno inseto vinha, há tempos, intrigando naturalistas e curiosos - os pulgões ${ }^{2}$.

\footnotetext{
2 Afídeos, popularmente conhecido como pulgões, são insetos da ordem hemíptera, que vivem de uma dieta de seiva de plantas. Hoje se sabe que compreendem aproximadamente 4700 espécies entre três famílias principais: Aphididae, Adelgidae e Phylloxerida (DAVIS, 2012).
} 


\section{O enigma do pulgão}

No início do século XVIII, os naturalistas consideravam que a reprodução sexual em animais envolvia dois indivíduos que copulavam. Porém, desde o século anterior, alguns estudiosos acadêmicos e amadores realizaram observações do pulgão que pareciam indicar uma transgressão dessa regra, motivando diversas investigações sobre a reprodução desses organismos.

O holandês Johannes Goedaert ${ }^{3}$ (1617-1668) não conseguiu observar a cópula entre esses insetos, porém, ao notar a curiosa associação entre os pulgões e as formigas, considerou que os pulgões nasciam de um tipo de líquido que as formigas espalhavam sobre as plantas (PLATEAU, 1868, p. 20). O naturalista holandês Antonie Philips van Leeuwenhoek (1632-1723), mesmo não tendo encontrado nenhum macho entre os pulgões, afirmou que eles produzem "filhotes vivos", isto é, que nascem após serem formados no interior do corpo da mãe. Ele apenas mencionou esse fato, sem maiores explicações derivadas de observações ou experimentos (PHILLIPS, 1903, p. 295). Na Itália, o naturalista Giacinto Cestoni (1637-1718) havia afirmado que os pulgões eram hermafroditas, pois observou que geravam descendentes, mesmo sem jamais terem sido vistos copulando (PRESTES; MARTINS, 2014, p. 346). O francês Claude-Joseph Geoffroy (1685-1752) afirmou que uma espécie de pulgão com asas era vivípara, como indicara Leeuwenhoek. Ao observar o nascimento desses pulgões, Geoffroy percebeu que possuíam a mesma forma da mãe, porém sem asas; no entanto, ao se

\footnotetext{
${ }^{3}$ Goedaert publicou, entre 1662 e 1667, três volumes da obra Métamorphoses naturelles ou Histoire des insectes observée tres-exactement suivant leur nature \& leurs propriétés (Metamorfose natural ou história dos insetos observados na natureza e suas propriedades), incluindo observações sobre metamorfose em insetos (GOEDAERT, 1700).
} 
desenvolver, eles se tornavam alados (RÉAUMUR, 1737, p. 326). As observações de Geoffroy trouxeram um novo problema, pois era sabido, por meio de analogias com outros insetos, que indivíduos sem asas eram fêmeas, indivíduos com asas eram machos (RÉAUMUR, 1737, p. 324). As observações de Geoffroy com pulgões alados lançaram mais dúvidas sobre a história de geração desses pequenos insetos. Por sua vez, Réaumur dedicou-se intensamente ao estudo da história natural desses insetos, descrevendo os resultados das suas observações na nona memória do terceiro volume de suas Memoires pour servir a l'histoire des insectes, de 1737. Ao longo de 69 páginas, ele ofereceu detalhes morfológicos e hábitos de espécies diferentes de pulgões por meio de extensas, contínuas e variadas observações (RÉAUMUR, 1737, p. 283).

Os esforços de todos esses naturalistas não resolveram a questão. O mistério que ainda demandava solução trazia consigo novas incertezas. Diante delas, Réaumur perguntou: "Qual seria, afinal, o sexo dos pulgões com asas, e qual a serventia desses na família dos pulgões?" (RÉAUMUR, 1737, p. 324).

Para responder a questão, Réaumur tentou isolar um pulgão com asa a fim de observar o nascimento de um filhote, mas não teve sorte. Assim, ele empreendeu um novo procedimento:

Para se convencer que [esses pulgões alados] são vivíparos, basta pressionar próximo ao meio do ventre, forçando suavemente até que os pequenos corpos saiam pela parte de trás. Qualquer observador, usando uma lupa, que olhe os pequenos corpos, facilmente reconhecerá que os pulgões estavam formados e prontos para nascer. (RÉAUMUR, 1737, p. 326)

Réaumur repetiu as observações para garantir o estabelecimento da viviparidade nos pulgões. Esse compromisso de Réaumur com a regra metodológica da repetição da observação e 
experimento exemplifica uma das dimensões da Ciência Integral discutida por Allchin, a observacional. Assim, o episódio permite explicitar aspectos metacientíficos da investigação, envolvendo "replicação e tamanho da amostra", "papel do estudo sistemático" e "completude de evidências", relacionados, respectivamente, às esferas das "observações e medidas" e "experimentos" (ALLCHIN, 2013, p. 24).

A viviparidade não fornecia, contudo, nenhuma pista sobre o sexo desses indivíduos. Mesmo tento observado o nascimento de várias gerações de espécies diferentes de pulgões alados, ele não ousou decidir sobre o sexo desses insetos:

Até aqui, nós encontramos apenas fêmeas entre os pulgões, nunca encontramos insetos os quais pudéssemos considerar como machos; seriam, então, os dois sexos reunidos nesses organismos, como ocorre em caramujos? Parece que isso ainda não é suficiente, pois, vemos o acasalamento em caramujos; e sempre que eu observei os pulgões, tanto alados quanto os não alados, eu nunca percebi qualquer acasalamento [...]. O que é certo é que, se eles [pulgões alados] acasalam, é em boa hora, e o tempo do acasalamento seria, pelo menos, uma singularidade na história natural; [pois] os alados acasalam antes da última transformação [muda ou ecdise], por assim dizer, em sua infância. (RÉAUMUR, 1737, p. 327)

Essa dúvida continuou a inquietar Réaumur e o levou a pensar que talvez a reprodução dos pulgões fosse um caso excepcional.

\section{Exceção à regra?}

Para averiguar se o pulgão seria uma exceção à regra da geração animal, Réaumur elaborou um procedimento novo para 
a época, que ele chamou de "sequestração" e consistia em observar um organismo isolado de outros organismos. Ele esperou um pulgão dar à luz a um filhote e o isolou no momento seguinte ao seu nascimento - desse modo, garantia que o rebento não tivesse contato com qualquer outro indivíduo de sua espécie. Assim ele descreveu o método que ele desenvolveu:

Em um grande recipiente de vidro, eu plantei um repolho jovem, que não tinha ainda mais do que duas ou três folhas nascidas: sobre uma das folhas desse repolho eu coloquei uma mãe pulgão que eu tinha retirado de um grande pé de repolho; assim que ela deu à luz a um pequeno [filhote], eu removi a mãe de cima do repolho; cobri o recipiente com uma gaze fina de modo que o repolho jovem e o pulgão recém-nascido não fossem privados de ar e que fosse impossível a qualquer outro pulgão entrar no recipiente. (RÉAUMUR, 1737, p. 329)

Apesar dos cuidados, o filhote não se desenvolveu até a idade reprodutiva. Réaumur repetiu essa experiência quatro ou cinco vezes, e o filhote que sobreviveu por mais tempo chegou ao nono dia, enquanto outros pereceram no terceiro ou quarto dia. Os insucessos levaram Réaumur a abandonar a questão, mas, como era de seu costume, ele propôs o desafio a quem desejasse investir: "Eu tentei essa experiência várias vezes, mas ela não foi bem-sucedida. Porém relato o que eu fiz, porque as mesmas tentativas podem ser feitas por outros com mais sucesso" (RÉAUMUR, 1737, p. 329).

\section{Charles Bonnet e o enigma dos pulgões}

Passados três anos desde que iniciou as observações com insetos, Bonnet, então estudante de Direito, se dedicava 
também à leitura do terceiro volume das Memoires de Réaumur. Ao se deparar com o problema da reprodução dos pulgões, decidiu investigar pessoalmente a questão: "Animado pelo convite de Sr. Réaumur, em 1740 eu comecei a tentar essa experiência com o pulgão do carvão"4 (BONNET, 1745, p. 29).

A atitude de Bonnet, mesmo ocupado com o seu curso de Direito, é oportuna de ser realçada por indicar uma das esferas da dimensão "conceitual" da Ciência Integral de Allchin (2013, p. 24). Entre elas, o "espectro de motivações para fazer ciência", fruto de sua intensa busca pelo conhecimento e admiração pela história dos insetos.

Decidido então a refazer o estudo de Réaumur, Bonnet iniciou a experiência com esse pulgão, em Genebra, às 5 horas da tarde do dia 20 de maio de 1740. Após ter imaginado um meio seguro de manter o organismo isolado, assim descreveu e ilustrou (Figura 2) o procedimento adotado:

Em um vaso de flores [figura 1], preenchido com terra comum, eu enterrei, até o seu gargalo, uma garrafa de vidro [figura 2] cheia d'água. Eu inseri nessa garrafa um pequeno ramo de evônimo [figura 3], contendo não mais que cinco ou seis folhas, depois de examiná-las de todos os lados com a maior atenção. Em seguida, eu depositei sobre uma dessas folhas um pulgão cuja mãe, desprovida de asas, acabara de dar à luz sob meus olhos. Eu cobri o pequeno ramo com um pote de vidro [figura 4], cujas bordas encostavam perfeitamente sobre a superfície da terra do vaso

\footnotetext{
${ }^{4}$ Pulgão do carvão (Aphis fabae) ou pulgão negro da fava é conhecido por sua coloração escura. Até hoje ele é considerado como o hospedeiro principal do evônimo (Evonymus europaeus) ou fusain, em francês (BLACKMAN; EASTOP, 2007, p. 9).
} 
de flores, certo de que o estava conduzindo como Danae, presa numa torre de marfim por ordem de Acrísio $^{5}$. (BONNET, 1745, p. 27)
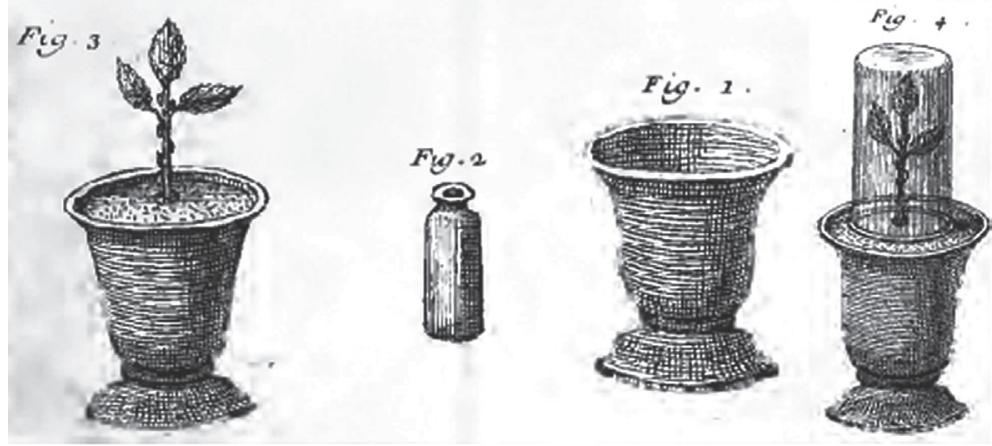

Figura 2 - Ilustração do procedimento utilizado por Bonnet para manter o pulgão isolado. Note-se que, embora numeradas, as figuras não são ordenadas segundo o padrão atual, da esquerda para a direita.

Fonte: Bonnet (1745, prancha 4, p. 293).

Bonnet registrou diariamente as observações feitas de hora em hora e em intervalos menores, começando às quatro ou cinco da manhã e findando às nove ou dez horas da noite (BONNET, 1745, p. 28). Naquele momento, ele concentrou inteiramente a sua atenção no pequeno inseto. Enquanto os pulgões que Réaumur havia observado não avançaram além da segunda troca de pele, perecendo pouco tempo depois, Bonnet (1745, p. 31) observou o seu pulgão alcançar a maturidade depois de quatro trocas de pele, "um trabalho aparentemente penoso".

\footnotetext{
${ }^{5}$ A metáfora citada por Bonnet refere-se ao mito grego do rei Acrísio, que, desapontado por não ter filhos homens que o sucedessem no trono, decidiu pedir ajuda a um oráculo. A resposta recebida foi que um neto iria matá-lo. Assim, para evitar que sua filha, Danae, tivesse filhos, Acrísio a trancou isolada em uma torre.
} 
O mérito de Bonnet, que adaptou o dispositivo de isolamento do organismo idealizado por Réaumur, foi o de ter obtido êxito nessa criação artificial de pulgões, o que certamente representa superação de dificuldades técnicas que o naturalista francês não havia conseguido resolver (SIGRIST, 2001, p. 427). Bonnet exerceu longos e contínuos períodos de observação do pulgão, produzindo um registro diário do comportamento de seu objeto de estudo. Nota-se que a preocupação dada à "acurácia" e "precisão" nas observações refletem outro aspecto da dimensão observacional do fazer científico (ALLCHIN, 2013, p. 24).

O que vem a seguir é o que Bonnet chamou de "os fatos mais interessantes da vida de nosso solitário", o pulgão (BONNET, 1745, p. 38).

\section{A multiplicação sem acasalamento}

Estabelecida a eficiência do procedimento de isolamento do organismo, e garantida simultaneamente a sua sobrevivência, Bonnet passou então a investigar se esses insetos seriam "suficientes a si mesmos" (BONNET, 1745, p. 116). Após uma longa vigília de observações, no dia 10 de junho de 1740 a sua paciência e dedicação foram recompensadas:

Cerca de sete horas da manhã, com grande contentamento, eu vi o nascimento; e desde logo eu julguei que devia chamá-lo de pulgãozinho. A partir desse dia, e durante os 21 dias seguintes, nasceram 95 filhotes, todos bem vivos e a maior parte nascendo diante dos meus olhos. Eis uma Tabela [figura 3] em que assinalei com a maior exatidão que me foi possível o dia e hora do nascimento de cada um desses pulgões. $\mathrm{O}$ asterisco indica os nascimentos que ocorreram 
em momentos em que eu não estava observando. (BONNET, 1745, p. 39)

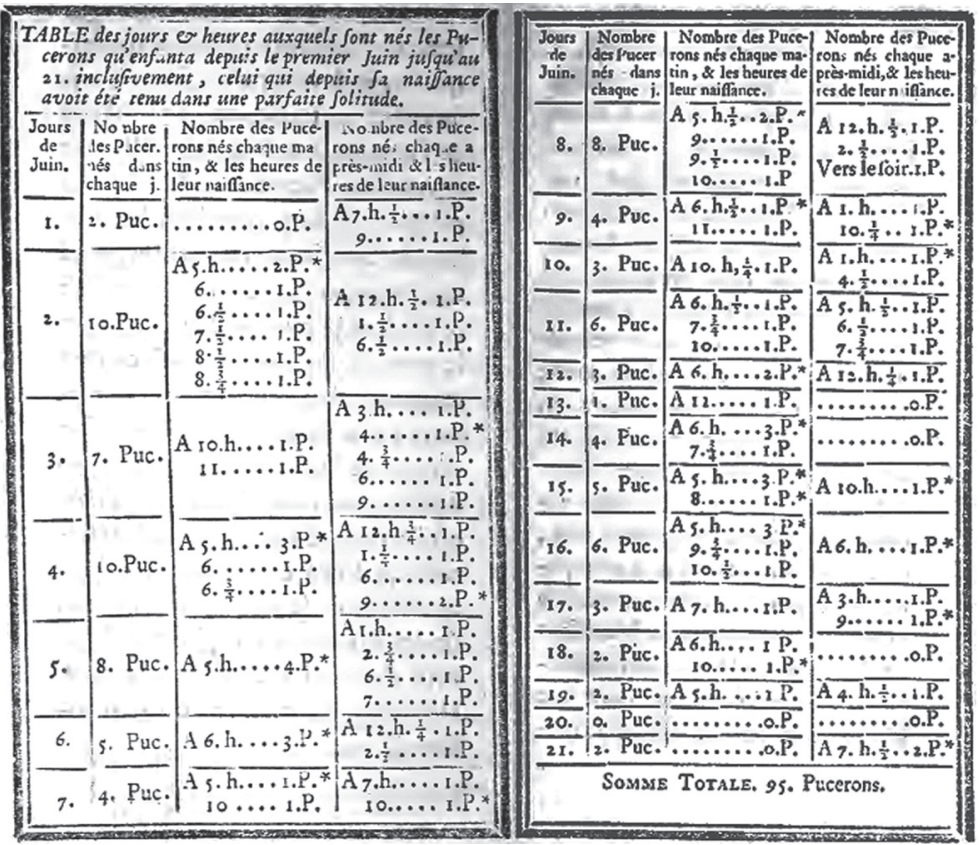

Figura 3 - Registro de nascimento dos pulgões. Da esquerda para a direita, as colunas representam dia de nascimento, quantidade, número de pulgões e hora de nascimento antes do meio-dia e após o meio-dia, respectivamente.

Fonte: Bonnet (1745, p. 40).

Além da preocupação de produzir uma narrativa detaIhada das suas observações, Bonnet (1745) também apresentou um cuidado particular ao organizar alguns dados obtidos na forma de tabelas. Essa prudência metodológica, que estava sendo estabelecida pelos naturalistas observadores e experimentadores do século XVIII, se configura como uma dimensão sociocultural da ciência que pode ser discutida com os estudantes, 
enfatizando o papel da "comunicação" com respeito às "normas para o manuseio de dados científicos" (ALLCHIN, 2013, p. 24).

A estratégia de registro diários das investigações adotada por Bonnet, desenvolvendo ilustrações com legendas e tabelas, facilitava tanto a reunião de informações quanto a redução de palavras - uma indicação de que a prática da condução de observações e experimentos em série demandava uma abordagem econômica de escrita científica. Essa nova forma de apresentação de dados era um método muito menos prolixo na apresentação de informações, que se generalizou na segunda metade do século XVIII (RATCLIFF, 2004, p. 569-571).

Bonnet foi capaz de lograr êxito ao concluir uma experiência que outros naturalistas fracassaram. Entusiasmado pela descoberta, ele decidiu reportar os detalhes das observações a Réaumur. O naturalista da Academia de Ciências de Paris não deixou de reconhecer a contribuição de Bonnet e de sugerir ainda novas observações:

Seguro da satisfação que as observações do Sr. Bonnet fariam à Academia [de Ciências de Paris], logo comecei a ler a sua carta datada de 13 de julho [1740] em que estavam os detalhes [das observações]. Ficou aparente para toda a Academia que o Sr. Bonnet tinha tomado as precauções e cuidados [...], no entanto, ele detinha apenas uma experiência, que embora muito bem-feita, não era suficiente para evitar dúvidas em relação a um ato contrário a uma lei geral que parecia estabelecida pelo apoio unânime dos fatos até então vistos. Temos muitos exemplos de circunstâncias que escaparam aos olhos perspicazes e atentos. A Academia, portanto, não poderia deixar de desejar que o mesmo experimento fosse repetido pelo Sr. Bonnet, muitas vezes, e com as mais diferentes espécies de pulgões que fosse possível. (RÉAUMUR, 1742, p. 537) 
A excepcionalidade do evento levou Réaumur (1742, p. 29) a divulgar a descoberta a outros três "excelentes observadores", para que repetissem a experiência: o francês Gilles-Augustin Bazin (1681-1754); o genebrês (e primo de Bonnet) Abraham Trembley (1710-1784) e o holandês Pierre Lyonnet (1708-1789) - "um dos mais perspicazes observadores de insetos" (RÉAUMUR, 1742, p. 538). Os três naturalistas se empenharam em repetir as observações de Bonnet a fim de certificar a sua veracidade. Usando métodos diferentes de isolamento e espécies diversas, todos confirmaram a mesma conclusão: pulgões são gerados sem a necessidade de qualquer cópula.

Por se tratar de caso singular, o evento da reprodução dos pulgões necessitou de mais evidências produzidas por outros "especialistas". Nesse ponto, é importante ressaltar a dimensão sociocultural, relacionada aos aspectos das "instituições" e da relevância da "revisão por pares" (ALLCHIN, 2013, p. 24), a fim de corroborar aquilo que seria uma exceção à regra da reprodução animal. Ademais, para essa "validação por pares", o próprio Bonnet sabia que a repetição dependia de um relato minucioso dos métodos empregados:

Nós vivemos em um século em que as Observações, sobretudo aquelas que são objetos de fatos singulares, precisam ser detalhadas, e até certo ponto, repetidas várias vezes. Não queremos saber apenas os resultados das Observações ou Experiências. Queremos saber como o Observador chegou à descoberta que ele relata. As particularidades [recursos] que estão disponíveis no percurso e os obstáculos que ele encontrou. (BONNET, 1745, p. 51)

No outono de 1740, enquanto Bonnet repetia e conduzia novas observações com outras espécies de pulgões, um fato 
inusitado chamou a sua atenção. Ele constatou que uma dessas espécies era capaz de acasalar! Fato concomitantemente observado por Lyonnet e Trembley, na Holanda. A observação da cópula nessa espécie trouxe novamente a dúvida sobre a multiplicação sem acasalamento e Trembley escreveu a Bonnet conjecturando a hipótese: "Em casos distantes do ordinário, todas as tentativas são permitidas. Quem sabe se um único acasalamento não seria suficiente para várias gerações?" (TREMBLEY, 1741 apud DAWSON, 1987, p. 89; BONNET, 1745, p. 66).

Para responder a pergunta de Trembley, Bonnet realizou a sua maior série de exaustivas e contínuas observações. TrabaIhando com espécies de pulgões do sabugueiro, da banana, do carvalho e do carvão, obteve, da primeira e da terceira, cinco e depois nove gerações consecutivas de pulgões nascidos sem qualquer acasalamento. Sobre essas observações, Bonnet considerou:

Somos forçados a admitir e concordar que os pulgões perpetuam sua espécie absolutamente sem acasalamento ${ }^{6}$, ou admitir que um único acasalamento sirva, ao menos, a nove gerações consecutivas; o que seria admitir algo igualmente distante às regras ordinárias [...]. Não creiam, no entanto, que eu digo isso para me dispensar de continuar com essas experiências e estendê-las a um número maior de Gerações [...]. Eu não me desesperaria, porém, de tentar colocar em solidão, ao menos, até a trigésima geração desses pequenos insetos [...] [Entretanto] eu não observei diferenças muito sensíveis com relação ao tamanho

\footnotetext{
${ }^{6}$ Essa forma de reprodução sem acasalamento em pulgões (afídeos) é atualmente conhecida como partenogênese, termo cunhado apenas em 1849 por Richard Owen (OWEN, 1849). Todas as espécies conhecidas são ciclicamente partenogenéticas, isto é, sazonalmente alternam entre uma ou várias gerações em que os ovos não fertilizados se desenvolvem em fêmeas e uma geração sexual em que ovócitos devem ser fertilizados por um espermatozoide (DAVIS, 2012).
} 
entre os pulgões das últimas gerações e daquelas gerações precedentes [...]. A segunda coisa que eu observei é que os pulgões alados de cada Geração foram todos produzidos sem que eu os jamais visse acasalando uns com os outros ou com os não-alados [sic]. (BONNET, 1745, p. 102-103)

Para fortalecer seu argumento, Bonnet conduziu "séries de experiências" por meio de repetições e variações, a fim de garantir a estabilidade e analisar a extensão do "fato novo" (SIGRIST, 1994, p. 430). As "séries de experiências", características dos experimentadores do século XVIII, remetem ao planejamento de um conjunto de experiências ordenadas, com o objetivo de corroborar uma hipótese e validar uma teoria (RATCLIFF, 1995 apud PRESTES, 2003, p. 310).

Assim, a série experimental de Bonnet, sistematizada num conjunto de observações coordenadas, não era uma simples acumulação de eventos destinados a evidenciar os "fatos". Pode-se dizer que a série possuía uma abordagem analítica que reside em dois tipos de observações ou experimentos: (1) as experiências discriminatórias que visam validar/invalidar uma hipótese ou para estabelecer a existência de um fato, e esse é o caso da experiência da multiplicação sem acasalamento, que introduziu um fato novo e ao mesmo tempo destituiu o dogma da universalidade da reprodução sexual em animais; (2) experiências generalizantes, que têm uma função de análise, úteis para determinar a extensão de um fato, estabelecer as suas diferentes variantes, bem como atestar a sua estabilidade e reprodutibilidade em diferentes lugares e circunstâncias (SIGRIST, 1994, p. 430).

A preocupação em apresentar uma narrativa detalhada da descoberta apresentada por Bonnet se configura como uma 
retórica científica, que pretende fazer do leitor uma testemunha virtual, suscetível a repetir todas as observações e experiências. Além de apontar as minúcias dos procedimentos utilizados, ilustrar os dispositivos e precauções tomadas, ele alimenta a sua história com fragmentos importantes do seu diário de "laboratório" apresentados sob a forma de ilustrações e tabelas a fim de aumentar a fidelidade da narrativa (SIGRIST, 1994, p. 437).

\section{Considerações finais}

Ao longo deste capítulo, foi analisada a "descoberta" da multiplicação sem acasalamento em pulgões realizada por Charles Bonnet a partir de sua interlocução com naturalistas da época, especialmente o francês Réaumur. Os estudos mencionados estabeleceram que as fêmeas de várias espécies de pulgões são capazes de se reproduzir sem cópula, fenômeno denominado "partenogênese" em 1849. Esse fato gerou um impacto na época devido a contrariar a regra geral de reprodução sexuada entre os animais.

A narrativa do episódio histórico contendo a descrição e análise das observações e experimentos foi acompanhada por inserções sobre aspectos metacientíficos envolvidos, conforme as dimensões da Ciência Integral, propostas por Allchin. Considera-se que esta narrativa histórica, enriquecida pelos aspectos metacientíficos indicados, constitui-se um material didático que oferece uma abordagem explícita e reflexiva em sala de aula de ciências e biologia sobre aspectos de como a ciência funciona. Espera-se que essa possa ser uma contribuição para incrementar a alfabetização cientifica dos estudantes. 


\section{Referências}

ALLCHIN, Douglas. The Minnesota Case Study Collection: New Historical Inquiry Case Studies for Nature of Science Education. Science and Education, v. 21, n. 9, p. 1263-1281, 2012.

- Teaching the Nature of Science: Perspectives \& Resources. Saint Paul, MN: SHiPS Educational Press, 2013.

BLACKMAN, Roger L.; EASTOP, Victor F. Taxonomic Issues. In: VAN EMDEN, Helmut F.; HARRINGTON, Richard (Ed.). Aphids as Crop Pests. Cambridge, MA: CABI, 2007. p. 1-22.

BONNET, Charles. Traité d'insectologie ou Observations sur les Pucerons. Paris: Chez Durand, 1745.

- Oeuvres d'Histoire Naturelle et de Philosophie. Neuchâtel: Librarie du Roi, Chez Samuel Fauche, 1779. v. 2.

ERDURAN, Sibel; DAGHER, Zoubeida. Reconceptualizing the Nature of Science for Science. Science \& Education, v. 25, n. 1, p. 1-2, 2016.

DAVIS, Gregory K. Cyclical Parthenogenesis and Viviparity in Aphids as Evolutionary Novelties. Journal of Experimental Zoology Part B: Molecular and Developmental Evolution, v. 318, n. 6, p. 448-459, 2012.

DAWSON, Virginia P. Nature's Enigma: The Problem of the Polyp in the Letters of Bonnet, Trembley and Réaumur. Philadelphia: American Philosophical Society, 1987.

FITZGERALD, Terrence D. Role of Trail Pheromone in Foraging and Processionary Behavior of Pine Processionary Caterpillars 
Thaumetopoea pityocampa. Journal of Chemical Ecology, v. 29, n. 3, p. 513-532, 2003.

GOEDAERT, Johannes. Metamorphoses naturelles, ou, Histoire des insectes: observée tres-exactement suivant leur nature \& leur proprietez: avec les figures en taille-douce gravées d'aprés nature. Amsterdam: Chez George Gallet, 1700.

HATCH, Robert. A. Correspondence Networks. In: APPLEBAUM, Wilbur (Ed.). Encyclopedia of the scientific revolution: from Copernicus to Newton. New York: Garland Publishing, 2000. p.168-170.)

LEONI, Simona Boscani. Men of exchange: creation and circulation of knowledge in the swiss republics of the eighteenth century. In: HOLENSTEIN, André; STEINKE, Hubert; STUBER, Martin (Ed.). Scholars in action: The practice of knowledge and the figure of the savant in the 18th century. Leiden: Brill, 2013. v. $2,507-533$.

MARTINS, Lilian Al-Chueyr Pereira. A História da Ciência e o Ensino de Biologia. Ciência \& Ensino, v. 5, p. 18-21, 1998.

MARTINS, Roberto A. Introdução: A história das ciências e seus usos na educação. In: SILVA, Cibelle C. (Ed.). Estudos de história e filosofia das ciências: subsídios para aplicação no ensino. São Paulo: Livraria da Física, 2006. p. 11-34.

MATTHEWS, Michael R. Science Teaching: The Role of History and Philosophy of Science. New York: Routledge Chapman \& Hall, 1994.

MCCLELLAN, James. Scientific institutions and the organization of science. In: PORTER, Roy (Ed.). The Cambridge History of 
Science: Eighteenth-Century Science. Cambridge, UK: Cambridge University Press, 2008. p. 87-106.

METZ, Don. We now interrupt the story: mediating student learning using historical stories. In: NINTH INTERNATIONAL HISTORY, PHILOSOPHY AND SCIENCE TEACHING CONFERENCE, june 24-28 2007, Calgary, Canadá. Anais... Calgary: University of Calgary, 2007. p. 1-15. Disponível em: <https://goo.gl/j7fj7D>. Acesso em: 18 out. 2016.

OWEN, Richard. On parthenogenesis, or The successive production of procreating indivduals from a single ovum. London: J. Van Voorst, 1849.

PHILLIPS, Everett. A Review of Parthenogenesis. Proceedings of the American Philosophical Society, v. 42, n. 174, p. 275-345, 1903.

PLATEAU, Félix. Études sur la parthénogenèse. Gand: C. AnnootBraeckman, 1868.

PRESTES, Maria Elice B. A biologia experimental de Lazzaro Spallanzani (1729-1799). 2003. 393 f. Tese (Doutorado em Educação) - Faculdade de Educação, Universidade de São Paulo, São Paulo, 2003.

. Definição e classificação de insetos por René-Antoine Ferchault de Réaumur. Filosofia e História da Biologia, v. 3, n. 1, p. 263-284, 2008.

PRESTES, Maria Elice Brzezinski; MARTINS, Lilian Al-Chueyr Pereira. Observação e Experimentação Animal no Século XVIII: os estudos de Abraham Trembley sobre a hidra. Acta Scientiae, v. 16, n. 2 , p. 345-369, 2014. 
RATCLIFF, Marc. Abraham Trembley's strategy of generosity and the scope of celebrity in the mid-eighteenth century. Isis, v. 95, n. 4, p. 555-575, 2004.

- Experimentation, communication and patronage: a perspective on René-Antoine Ferchault de Réaumur (16831757). Biology of the cell, v. 97, n. 4, p. 231-233, abr. 2005.

RÉAUMUR, René Antoine Ferchault de. Memoires pour servir a I'histoire des insectes. Paris: L'imprimerie royale, 1734. v. 1. Paris: L'imprimerie royale, 1736. v. 2. . Paris: L'imprimerie royale, 1737. v. 3. . Paris: L'imprimerie royale, 1742. v. 6.

RODRIGUE, Jean-Paul; COMTOIS, Claude; SLACK, Brian. The Geography of Transport Systems. 3. ed. New York: Routledge, 2013.

SIGRIST, René. L'expérimentation comme rhétorique de la preuve : L'exemple du Traité d'insectologie de Charles Bonnet. Revue d'histoire des sciences, v. 54, n. 4, p. 419-449, 2001.

TERRALL, Mary. Following insects around: tools and techniques of eighteenth-century natural history. The British journal for the history of science, v. 43, n. 4, p. 573-588, 2010. 